\title{
15 \\ A CYBERNETIC APPROACH TOWARDS \\ KNOWLEDGE-BASED COORDINATION \\ OF DYNAMICALLY NETWORKED \\ ENTERPRISES
}

\author{
Thomas Fischer and Sven-Volker Rehm \\ Institute of Textile Technology and Process Engineering Denkendorf \\ of the German Institutes for Textile and Fibre Research Stuttgart, \\ Department Management Research, GERMANY \\ \{thomas.fischer,sven,rehm\}@itv-denkendorf.de
}

\begin{abstract}
In the scope of the European Research Framework, at ITV Denkendorf new concepts, methodologies and ICT architectures for cooperation and coordination in multi-stage value added chains have been developed and applied. Starting from a cybernetic approach, methods of knowledge-oriented management have been used that support the cooperative planning of production network resources and their allocation to dynamic business processes for networked organizations.

In particular, methods for network analysis, process-oriented modeling and distribution of Organizational, Procedural and Operational Knowledge have been developed, allowing for a flexible network configuration and coordination. They have been validated and implemented in several production networks of textile small and medium enterprises (SMEs) as part of a European research project, on basis of e-business collaboration platforms.
\end{abstract}

\section{ECONOMIC SITUATION AND ORGANIZATIONAL RELEVANCE}

The textile and clothing companies in Europe traditionally cultivate a cooperative management culture along a multi-stage value added chain, networked horizontally and vertically, which is very similar to the paradigm of the Virtually Extended Enterprise. They cooperate inside grown clusters, as well as between these clusters (Porter, 1990; Porter, 1998), by creating dynamic enterprise networks (Antrecht, 2002). Hence, every textile product is the result of cooperation between partners with different competences and corresponding contributions.

Taking into account today's demands for complexity and diversity of goods and services, their acquisition and marketing, the world-wide scope of business relations and the drastically shortened product life cycles, the majority of textile companies can pursue a save way into the future only by adopting appropriate partnerships - 
within different organizational and legal forms, generally speaking in the form of dynamic networks, as a collective term for a variety of co-operational forms (Kaluza et al., 2000). For the framework of management activities inside a single enterprise, this complex environment causes a growing pressure for innovation (Scheer, 2003) considering new products and services, new materials and production processes as well as new organizational forms throughout the product life cycle.

The latter aim at introduction of "smart" organizational forms, in their instances as supply network, extended enterprise or virtual enterprise. Successful will be the one, who does not only trust in realizing a single element of this innovation space (Filos et al., 2001), but who starts from a holistic approach (Fischer et al., 2002a). This applies in particular for the entrance to the world of e-business with all its facets (Timmers, 2003; Luczak et al., 2003). The most successful companies will need to operate on basis of collectively, shared information and coordinated communication (Fly, 2000) in the scope of a knowledge and service society.

Therefore, in order to assure future competitiveness, they are forced to put into practice the appropriate infrastructure in terms of concepts, methods and (internet-) technologies for Dynamically Networked and Virtual Organisations (Stellmach, 2003, Fischer et al., 2003).

The digital economy has created a continuously, complex and changing environment. Also textile networks orient themselves at global perspectives, and become larger, exceedingly dynamic and increasingly "virtual" in their ability to offer and to apply products and services, for which several partners contribute functionalities. The partnerships required carry the problems of quicker collaboration, quicker retrieval and contacting of partners, the engineering of cooperative processes and the matter of trusted relationships. This demands new organizational abilities and competences from the companies (Filos et al., 2001). They become "internet-worked" (Verticalnet, 2000) and they start to substitute traditional hierarchies; the networks are of a new quality. Competitiveness however, will be depending rather on the ability for organizational adaptation to the dynamics of textile products and business relations between textile companies, distributors and sales markets, than on procedural efficiency (Hammer et al., 1999; Hammer, 2001).

The management of this organizational change therefore is in the limelight and has to be supported by appropriate concepts, methods and technologies. These have to orient themselves at the cooperation types, cooperation objectives and tasks and moreover, at the situation of the individual enterprise. By doing this, an alignment to the complexity of the environment and the dynamics of the management task can be achieved (Coase, 1988; Rayport et al., 1995; Ashby, 1956).

In the European community research project TEXTERM (Textile Extended Enterprise Resource Management), for the area of knowledge-based coordination of production planning tasks, appropriate approaches have been developed, which are further outlined in this article.

\section{RESEARCH APPROACH}

\subsection{Knowledge-based Network Manufacturing Management}

Taking into account the multi-stage topology of the textile and clothing value added 
chain, the challenge for knowledge-based coordination of production planning tasks in Dynamically Networked Enterprises (DNE, see Figure 1) evolves against the background of two basic elements: Network manufacturing management on the one hand, and knowledge-based management on the other.

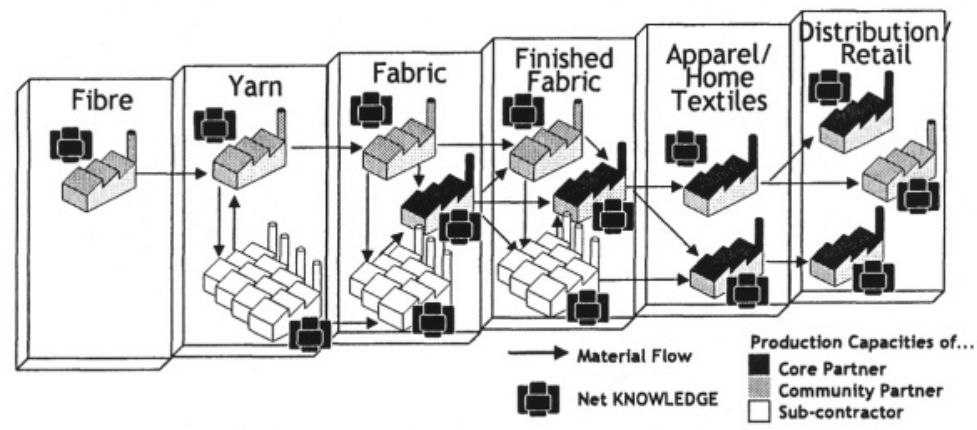

Figure 1 - The challenge for knowledge-based coordination of production planning tasks in Dynamically Networked Enterprises: Knowledge-based Network Manufacturing Management

Network manufacturing management describes the challenge of coordinating production planning tasks in manufacturing networks. In particular, the selection of available capacities and of appropriate routes for transformation and supply processes within an Extended Enterprise manufacturing network is in the spotlight.

Through vertical integration of program planning and scheduling, as well as with horizontal integration by coordinated networking, a virtual capacity and compression effect is to be achieved (see Figure 2).

The resulting economy of time $\left(\Delta T^{*}\right)$ can be used on the one hand, to enable a significantly shortened delivery time, e.g. in cases of re-ordered products, or on the other hand, to start production as late as possible when trying to hit a pre-defined delivery date, e.g. during quantity changes on basis of market sales forecasts for a textile collection. Nevertheless, in order to make this idea applicable, the partners need certain kinds of knowledge about their network.

Knowledge-based management deals in this context with the challenge to enable improved network manufacturing (production) planning, based on the appropriate application and sharing of Organizational, Procedural and Operational Knowledge existing in the network. The organization of planning, coordination and monitoring of the transformation and supply process, adapted to the actual status of the network, shall be supported with state of the art e-business technologies, that make use of shared knowledge.

In particular, the three knowledge classes mentioned comprise the following factors, and describe the required knowledge about the network (Net KNOWLEDGE):

For networking dynamically, it is vital to chose quickly between existing or new processing routes across the network, in order to follow the rapidly changing demands of customers. Therefore, Organizational Knowledge ${ }^{i}$ answers the question: "Who are the right partners for co-operation?" It represents generic knowledge about manufacturing and supply networks, as well as knowledge about 
the inter- and intra-organizational system structure in existing "Virtually Extended Enterprises".

1. Traditional Proceeding:

stepwise Planning and Production

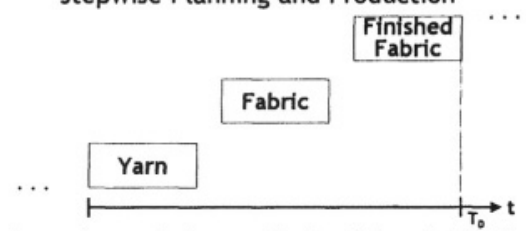

Successive production over fixed periods and within fixed capacity: $T_{D}=$ Delivery Time (Throughput Time)

3. New Approach: Horizontal Integration

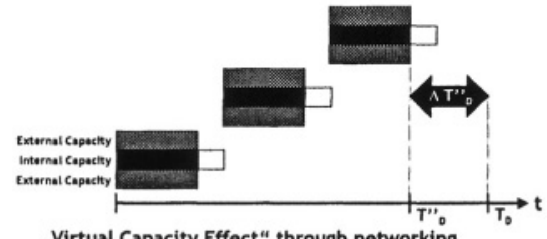

${ }_{\text {„Virtual Capacity Effect }}$ through networking

horizontally (parallel manufacturing of orders): $T^{\prime \prime}{ }_{D}<T_{D}$
2. New Approach: Vertical Integration

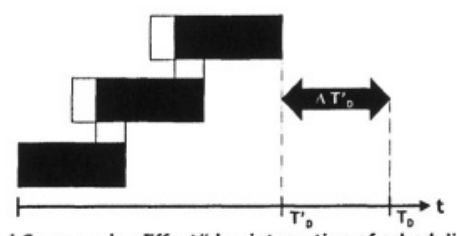

"Virtual Compression Effect" by integration of scheduling (overlapping manufacturing of orders): $T_{D}<T_{D}$

4. TEXTERM Approach: Dynamic Network Integration

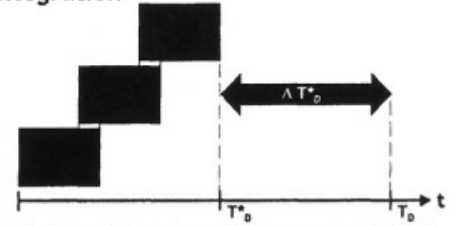

Combined "Virtual Capacity and Compression Effect" through dynamic network integration: $T_{0}{ }_{0} \ll T_{0}$

Figure 2 - Virtual capacity and compression effect through vertical and horizontal integration in Dynamically Networked Enterprises

Material properties and private knowledge about the production process influence the transformation processes throughout the entire value added chain and result in high demands for the manufacturers and their machinery. Accordingly, Procedural Knowledge asks "Which manufacturing service do the partners offer?" - in terms of all relevant objects, as there are materials, products, processes, applications and processing technologies.

Both, the on-line information about the status of all available resources, and the improvement of the planning and decision process, are prerequisites for co-operation along the supply chain. Consequently, Operational Knowledge supports information about "What are the status and the actual manufacturing opportunities of the network partners?"

\subsection{Cybernetic Research Approach}

While the pressure for innovation is set through demands in terms of new products and services, new materials and production processes as well as new organizational forms (see exposition), pro-active management and leadership from a holistic point of view can only be achieved by system integration and knowledge-orientation. A basis for this is set by modeling of systems and accompanying information. For the systems become increasingly complex (as networks of sub-systems), planning and control (leadership) of these systems demand for navigation inside the resulting networks and process-oriented coordination of activities, communication and interactions.

With focus on value-added networks, the value is created exceedingly through cooperation in ad hoc constellations with different integration levels (i.e. more or 
less close partnership). If networks allow an enterprise do act in this way, it can be spoken of Dynamically Networked Enterprises. For the single company, which then uses external competences (and knowledge), the picture of the Virtually Extended Enterprise is applicable.

The enlargement of such relationships however, requires profound knowledge, respectively a systematic opening and exploitation of information sources for gathering knowledge about potential partners, and next to potential opportunities, performance abilities, embracing also the cultural environment containing competencies and education of staff, or market evaluations for distribution.

As a result, the need for modeling topologies of value added networks and information about data and documents relevant for added-value, as well as their sources and carriers (media), is documented. These pieces of information have to be available in principle to all nodes in a network (Fischer et al., 2002b; Mesarovic et al., 1970), for an application scenario however, an appropriate choice of information must be taken (Rehm et al., 2002).

The second aspect mentioned, navigation in networks and process-oriented coordination of networking activities, concerns

- material and service flows,

- information flows, and

- money transactions.

The task of a network navigator will be, to decide on the appropriate routes through the network, by choosing the nodes (network partners), and their relations (the flows, see above). This design for system synthesis will impact on the later achieved performance of the network production planning and coordination, as it defines the boundary conditions for the production planning tasks. An inappropriate (ineffective) design, i.e. choice of wrong partners and routes, will lead to inferior performance even if efficiency inside the nodes is brought to an optimum. This decision depends on a variety of engineering aspects, which will be shown with the Net CONSULTANT methodology, below.

The cybernetic approach followed, however, is not a new one: Mesarovic, Macko and Takahara have pointed out in their "Theory of Hierarchical, Multilevel, Systems" (Mesarovic et al., 1970), that the engineering task described above is also relevant in less complex socio-economic control systems, e.g. the shop floor. The multi-level systems developed by these authors are an analogous development to the network decomposition shown in Figure 3.

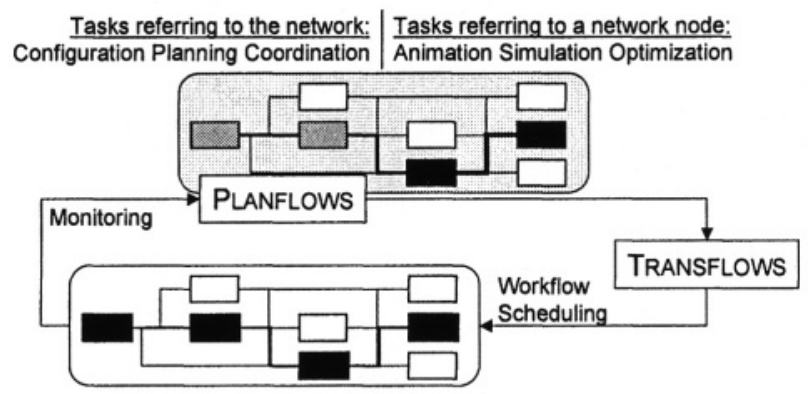

Figure 3 - Cybernetic approach for coordination of Dynamically Networked Enterprise networks 
Via PLANFLOWS, which are business processes for planning and coordination tasks, a network design answering to a current planning task is configured ${ }^{\mathrm{ii}}$. A coordination is enabled by controlling TRANSFLOWS between the network nodes, which are transformation and transaction processes, e.g. order processes to exchange production plans, requests, orders, etc. A realization is possible on collaboration platforms via work flpws. Monitoring will support control information for future coordination demands. .ii $^{\text {. }}$

\subsection{TEXTERM Project Scenarios}

The research work was carried out in the scope of a European Community research project (TEXTERM, 2004). In this project, three typical European networks of textile companies located in Germany, Italy and Spain, provided the settings and application fields for the development of the conceptions and methods presented in this article. These results have been developed and applied in close cooperation between research institutes, software providers and industrial partners.

During the three-year project, all networks, consisting of four, six, respectively 14 core companies, and their relationships to business partners (suppliers, customers, sub-contractors) throughout the textile major production stages as outlined in Figure 1, have been re-designed organizationally. For selected major network business cases the virtual extension has been implemented on a developed e-business collaboration platform, and with help of the developed tools and services. All of the networks by now continue their transformation process to become fully dynamically networked, with help of the methodologies described below.

\section{METHODS FOR VIRTUAL EXTENSION AND DYNAMIC NETWORKING}

An extensive modeling methodology has been developed, that aims at supporting the transformation towards a virtually extended and dynamically networking enterprise inside its manufacturing network. This project management methodology is called Net CONSULTANT. It has been designed to embrace the approaches for dynamic networking outlined, i.e. the views of knowledge orientation and process orientation for modeling and engineering of networks, as well as the approach to enable navigation in models and networks. Four project phases (Analysis, Design, Transfer, Operation \& Learning) are proposed, where each phase deals with five cybernetic elements identified for network engineering. For each of these elements, a number of model types have been identified, that allow to describe the information required to engineer the virtual extension and dynamic relations. The analyzed knowledge about the network (information) has been captured within models of a modeling repository (ARIS 2004), that provides the model types required.

In particular, the cybernetic elements consider the following network engineering aspects (see Figure 4):

1. The Network Topology refers to the overall setting of the extended enterprise network. The production stages contained in the network need to be defined, as well as the manufacturing and service opportunities of the partners. It therefore describes 
the system elements to be referred to, and answers the leading question: "Who is positioned where in the value added network?" In order to express this knowledge, Manufacturing/Service Network Maps, models of the Network Value Added Chain, Material/Service Trees or Community Organizational Charts can be used.

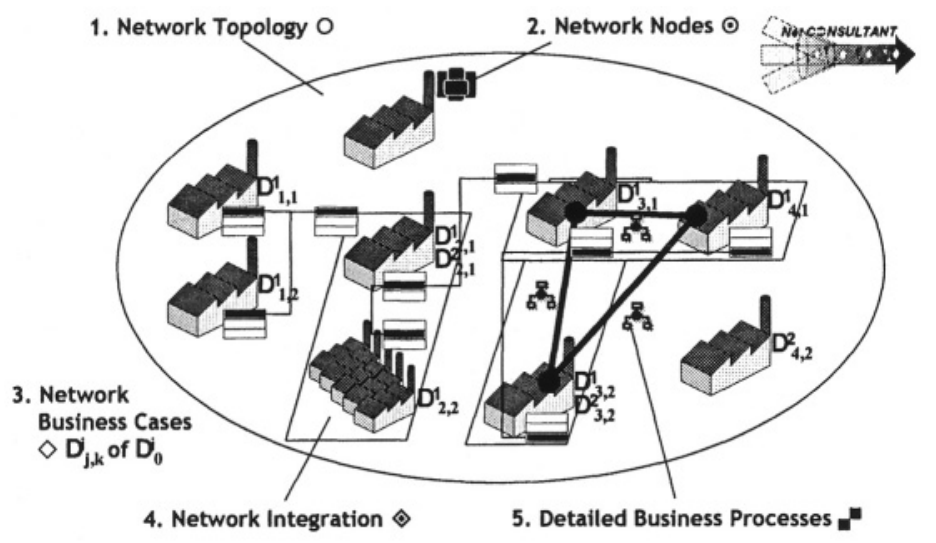

Figure 4 - Cybernetic elements of the Net CONSULTANT

2. The Network Nodes element takes a close look at the single system elements and their individual contributions, answering to the lead question: "Who processes how (technology) which material and offers which products and services?" Here, a detailed description of the technological abilities of the partner (machine types and processing technologies, etc.), the input, intermediate and throughput materials, as well as the ICT infrastructure must be given. In Figure 4, this is indicated by a small "knowledge" symbol (see also Figure 1).

3. The Network Business Cases element needs to define, which are the aspects that cause a consistent multi-stage business process, and which processes consequently can be defined in the network considered. A starting question may be, "Which are the main product groups / processing technologies / services in the network?" or "Which are major planning tasks / supply chain strategies followed?" In Figure 4, a set of parameters specifies for each node its participation to such a network business case. For each of these network business cases, the material and information flows as well as the money transactions, need to be mapped.

4. In order to analyze the existing and design the potential Network Integration, it can be started by examining the 1:1-relations between partners, vertically and horizontally. Aim is, to describe the close relationships between the system elements: According to the kind of information objects exchanged and the business processes existing in between them, Levels of Planning Integration (see Figure 5) can be defined, to structure the network business case at hand for supply network interrelations. In the project carried out, three of these levels have been defined:

\section{- Market Interaction}

In this commercial/sales-based co-operation, negotiations on basis of pro-duct/price catalogues and service/pro-duct/process specifications are carried out. 
- Planning Interoperation

This level describes a planning-based co-operation, where process and service agreements (e.g. reservation of machine capacity) allow discussions about the partner's actual capacity status and order allocation.

- Activity Integration

Within this shop floor cooperation level, the actual process status of the (virtually) extended enterprises is used to find the most efficient way to satisfy the customer.

In Figure 4, a tripartite rectangle indicates integration levels (top, middle or bottom layer blacked) for each partner and network business case.

As a general remark, distinguishing between these levels of sharing knowledge between business partners enables an appropriate design for co-ordinability of the network. The design must be oriented at the network business case considered, that carries individual boundary conditions for cooperation types, supply chain objectives and a network node's roles and tasks.

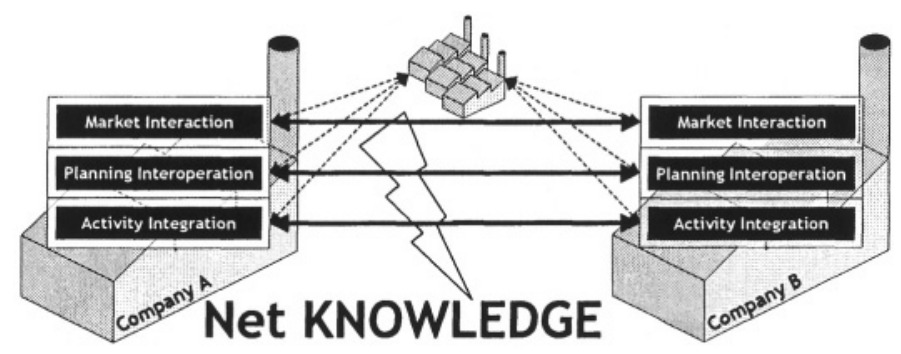

Figure 5 - Planning Integration: Co-ordination based on shared knowledge (Net KNOWLEDGE)

The integration areas do not only apply for 1:1-relations, but can be extended vertically and horizontally, to n:n-partnerships. In the TEXTERM project for instance, on the Finished Fabric production stage (see Figure 6), two shop floors have been integrated with a, third, central planning node in order to extend the production capacities.

The final objective of a network synthesis in the scope taken in this paper, is the design and implementation of appropriate integration strategies - dynamic networking - organizationally, and finally, work flows on a collaboration platform, that allow a process-oriented coordination throughout the network. This has been achieved in the project work on basis of the considerations considering the Network Integration element.

5. Detailed Business Processes need to be mapped, for master planning processes between the nodes, and for processes of a single node that interact with, or have significant influence on, other nodes' processes, e.g. when exchanging a plan. ERM or UML models ${ }^{\text {iv }}$ can be used to synthesize a consistent data base structure on basis of the information objects gathered.

To give an impression of the practical application of the cybernetic elements, Figure 6 displays an example for a Topology Model model type developed during the TEXTERM project. It is equivalent to one of the models created for the Italian network. In this network, approximately 65 network business cases have been iden- 
tified, that differ in the overall material flow (Figure 6: thick arrows), the information flows (Figure 6: arrows with abbreviations of the information objects exchanged), and the planning integration areas and levels (Figure 6: colored rectangles, e.g. "B-Z-M FF Planning", that indicate the company names, production stage and integration level). The name of the network business case is written on top (“Linea Prodotto \#2").

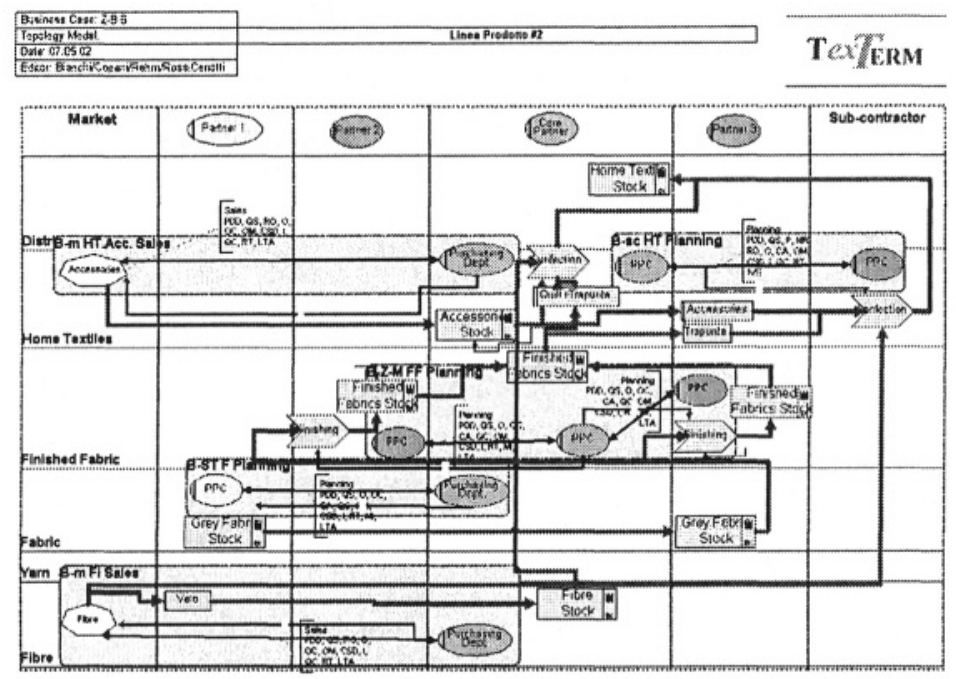

Figure 6 - Topology Model (model type) of a Network Business Case

\section{CONCLUSION}

In this article, a cybernetic approach towards knowledge-based coordination of production planning tasks in Dynamically Networked Enterprises has been presented. The conceptual part of this approach, including a differentiation between three kinds of knowledge, has led to the development of a decomposition methodology (Net CONSULTANT), that allows for a systematic analysis and modeling of manufacturing networks which intend to network dynamically, i.e. with differently intensified relations according to the situation at hand (method Planning Integration). The planning and transformation processes which can be designed accordingly (PLANFLOWS and TRANSFLOWS), can be used to coordinate the network as a network of Extended Enterprises on basis of an e-business collaboration platform.

\section{ACKNOWLEDGEMENTS}

The results presented in this paper have been developed as part of the European Commission GROWTH Project TEXTERM (Textile Extended Enterprise Resource Management System, No. GRD1-2000-26817). 


\section{REFERENCES}

1. Antrecht R. McK Wissen 01,1. Jahrgang 2002. Hamburg: brand eins, 2002.

2. ARIS. Architecture of Integrated Information Systems, http://www.ids-scheer.de/, 2004.

3. Ashby WR. An Introduction to Cybernetics. London: Chapman \& Hall, 1956, p. 121-191.

4. Coase RH. The Firm the Market and the Law. University ofChicago Press, 1988.

5. Filos E, Banahan EP. "Will the organisation disappear? The Challenges of the new economy and future perspectives". In E-Business and virtual enterprises: managing business-to-business cooperation, IFIP TC5/WG5.3 second Working Conference on Infrastructures for Virtual Organizations, Brazil 2000, p. 3-20, Camarinha-Matos LM, Afsarmanesh H, Rabelo RJ, eds. Norwell, Massachusetts: Kluwer Academic Publishers, 2001.

6. Fischer T, Rehm SV (2002a). How to Manage Complexity? New Technologies (ICT), Quality System and Human Ressources. ATI (Associazione Tessile Italiana) International Conference: Textile industry between globalization and complexity. Cernobbio, 01.06.2002.

7. Fischer T, Rehm SV (2002b). Wissensbasierte Koordination der Planung in Wertschöpfungsnetzwerken. Ein kybernetischer Ansatz. Conference of the German Society for Economic and Social Cybernetics 2002: Kybernetik und Wissensgesellschaft. Stuttgart-Vaihingen, 27.09.2002.

8. Fischer T, Rehm SV, Stellmach D, Fischer TV. Smart Organisations for Smart Textiles. TechtextilSymposium, Frankfurt a.M., 07.04.2003.

9. Fly JM. "The Insufficiency of Knowledge". In ITMF Annual Conference Report, Zurich, 2000.

10. Hammer M, Stanton S. "How Process Enterprises Really Work". In Harvard Business Review, Nr. 6, November/Dezember, 1999.

11. Hammer M. "The Superefficient Company". In Harvard Business Review, No. 8, September, 2001.

12. Kaluza B, Blecker T. "Management der Produktion und der Logistik in der Unternehmung ohne Grenzen". In Produktions- und Logistikmanagement in Virtuellen Unternehmen und Unternehmensnetzwerken, p.1-31, Kaluza B, Blecker T, eds. Berlin: Springer, 2000.

13. Luczak H, Bleck S, Quadt A. "Electronic business engineering - exploiting the potentials of a wireless world". In Int. J. Internet and Enterprise Management, Vol. 1, No. 1, p. 31-52,2003.

14. Mesarovic MD, Macko D, Takahara Y. "Theory of Hierarchical, Multi-level, Systems". In Mathematics in Science and Engineering, Volume 68. New York: Academic Press, 1970.

15. Porter ME. "Clusters and the new Economics of Competition". In Harvard Business Review, November/Dezember, 1998.

16. Porter ME. The Competitive Advantage of Nations. New York: Simon \& Schuster, 1990.

17. Rayport JF, Sviokla JJ. "Exploiting the Virtual Value Chain". In Harvard Business Review, November-December. Boston, 1995.

18. Rehm SV, Bender N. Kommunikation in einem wissensbasierten Koordinationssystem zur Planung in Wertschöpfungsnetzwerken. Conference of the German Society for Economic and Social Cybernetics 2002: Kybernetik und Wissensgesellschaft. Stuttgart-Vaihingen, 27.09.2002.

19. Scheer AW, Adam O, Hofer A, Zangl F. "Nach Cost Cutting - Aufbruch durch Innovation". In Information Management \& Consulting 18 (2003) Special Edition, p.6-13,2003.

20. Stellmach D. "Informationssysteme für die Textilindustrie". In ITB International Textile Bulletin 6/2003,2003.

21. TEXTERM. Textile Extended Enterprise Resource Management System, GROWTH 1998-2002, Project Reference G1RD-2000-00314. http://www.itv-denkendorf.de/texterm, 2004.

22. Timmers P. "Lessons from B2B E-Business Models". In Zeitschrift für Betriebswirtschaft, Ergänzungsheft 1/2003, p.121-140. Wiesbaden: Gabler-Verlag, 2003.

23. Verticalnet. Communication and Collaboration in a Landscape of B2B eMarketplaces. A Business White Paper. http://www.verticalnet.com, 2000.

\footnotetext{
i The authors ask to allow these specific definitions of terms for "knowledge about..." in contrast to existing knowledge community definitions.

ii This may be based on animation, simulation and optimization results for single or multiple shop floors. This aspect shall not be deepened in this paper.

iii Nevertheless, a compound description of network coordination for planning tasks is not possible with a hierarchical approach, as interactions and balancing of interests between hierarchically equal nodes (managers) will rely on self-organization principles of the system considered.

${ }^{\text {iv }}$ ERM...Entity Relationship Model; UML...Unified Modeling Language.
} 